\title{
Looking for Lesbian Motherhood
}

In December 1975, in Dallas, Texas, a lesbian mother named Mary Jo Risher lost custody of her nine-year-old son after her older, teenaged son gave testimony against her before a jury. I learned about the case when the San Francisco Chronide picked up the story; the paper's front page ran a close-up photograph of the mother's reaction when she heard the verdict. Her face was twisted in agony and the picture was absolutely heart-wrenching.

By the time I saw this picture, I had come to know another lesbian mother fairly well. She was a generation older than I, and she had lost custody of all three of her children in the early r 950 after her formcr husband called the police to report that she was sleeping with a woman. The police burst in, arrested both my friend and her partner, and removed the children to foster care, where they remained for several years. Only after the death of her former husband was she able to regain custody, and this only after managing to convince the court that the lesbian episode had represented a "phase" that had now ended.

This was the context within which I began the research that has led to this book. At the time I began this work, in 1977 , lesbian mothers and their families were not commonly discussed when the topic of the "changing American family" was raised. Most of my colleagues were confused when they learned of $\mathrm{my}$ intention to investigate lesbian mothers. Where would I find such people? How could a lesbian be a mother, they asked; wasn't that a contradiction in terms? ${ }^{1}$

The years since I began this work have been a time of transition for the particular population I worked with and for gay and lesbian people in general. Scholarship on gay and lesbian issues has emerged and 


\section{[2] Lesbian Mothers}

begun to receive academic recognition, contributing to the evolution of my intellectual and personal perspectives on these issues. ${ }^{2}$ They have been years during which homosexuality gained a public faccand an increasingly respectable one, at that -and lesbian motherhood has become a far more visible phenomenon.

During this period, public concern with gender, motherhood, and sexual orientation has changed. Feminism has given way, it seems, to the pluralism of "postfeminism"; ${ }^{3}$ at the same time, in the wake of the Reagan years, much popular discourse appears to be concerned with the rediscovery of so-called traditional values. ${ }^{4}$ During the years I was working on this project, the feminist critique of marriage and the family as sources of patriarchal domination appears to have collapsed, to be replaced by a more civil-rights-oriented emphasis on access to the economic and social privileges associated with these institutions. ${ }^{5}$

This shift has also involved a heightened awareness and celebration of what are taken to be the unique psychological and spiritual attributes of mothers, a shift intrinsic to a growing acceptance of a "cultural feminist" stance in the wider lesbian community ${ }^{7}$ and which has been influenced by the publication of books on motherhood with a lesbianfeminist slant. ${ }^{8}$ Homosexuality also has moved more squarely into public consciousness and may, depending on one's reading of current trends, be becoming more acceptable to the general population; 9 at the very least, its increasing visibility has meant that lesbian mothers are far less obscure today than they were when I began my research. ${ }^{10}$ Technology has become a relatively routine dimension of many women's reproductive lives, apparently expanding options and even permitting older and unmarried women-whether they be heterosexual or lesbian-more easily to contemplate not only motherhood but pregnancy and childbirth. The irony here is that while motherhood is culturally preferred and normalized, even for lesbians, mothers share with other women diminished economic options and low occupational status. At the same time that pronatalism has made a comeback, the society devotes few resources to child care, health care, education, housing, or other areas of vital concern to parents. ${ }^{11}$

This changing political climate, both in feminism and in the wider society, has had troubling consequences for my work. While my 
earliest concern was to validate the very existence of lesbian mothers and to show that they were "good enough" to keep their children, now my findings threaten to support a trend that seems to privilege motherhood over nonmotherhood, regardless of sexual orientation. The similarities between Iesbian and heterosexual mothers which I document, when considered from this perspective, suggest that motherhood, even more clearly than sexual orientation, defines womanhood, thereby intensifying the already existing bifurcation of women into mothers and nonmothers.

My early effort to gain a rightful place for lesbian mothers in the feminist reexamination of the family was only one example of a growing concern with carving out a place for lesbians in the expanding literature on gender and the family. This was also a period characterized by continuing feminist academic concern (both in anthropology and in other disciplines) with describing the nature of women's oppression across cultural boundaries and thereby legitimizing "women" as a domain for research. If women are a "group," characterized by universal, defining features, then sex oppression might be understood better and eventually defeated. ${ }^{12}$

What establishing the legitimacy and reality of lesbian mothers seemed to mean in 1976 , when I first began to think about this issue, was describing them and showing that they were not different from other mothers. What did I mean by "different"? Community concern at the time was centered on what seemed to be a growing number of custody cases, cases that lesbian mothers usually lost. The Mary Jo Risher case was only one of a number of highly publicized cases in which judges (or in the Risher case, a jury) assumed that lesbians could not, by definition, be adequate mothers, or, more seriously, that by definition they were likely to be "bad" mothers. Mothers in these cases either lost custody of their children or won custody under highly compromised conditions, often with the stipulation that they not live with their partners or not allow their children to have contact with them. ${ }^{13}$

The "Sandy and Madeleine case" provides a good example of the kinds of issues that tended to emerge in custody cases. Sandy and Madeleine were two mothers who met through their children's Sun- 


\section{[4] Lesbian Mothers}

day school. Both staunch fundamentalist Christians, they never thought that their relationship could be immoral, since "God had brought them together." In 1971 their ex-husbands joined together to try to obtain custody, going back to court repeatedly during the 1970 s each time judges gave the mothers custody with various sorts of conditions. Sandy and Madeleine felt so sure that their family was wholesome and normal that they had a film made about themselves, Sandy and Madeleine's Family, originally to be used in court, but later going into general circulation in lesbian communities around the country. ${ }^{14}$ The film emphasized the family's strong religious values, the importance the mothers gave to (particularly outdoor and athletic) activities with the children, and the warmth and nurturance of their relationships with their own and each other's children.

This film was only one of the indicators of the centrality of custody cases in the way the organized lesbian community approached motherhood at the time that I began thinking about these issues. For example, in a major popular collection of articles about the diversity of lesbian experience, Our Right to Love, only two out of some fifty articles deal with lesbian mothers. ${ }^{15}$ Onc focuses on legal, and spccifically on custody, problems, ${ }^{16}$ while the other, written by a psychologist, takes up the question whether and how to come out to one's children, an issue that derives some of its importance from the implications it may have in custody disputes. ${ }^{17}$

Given these concerns, I felt my responsibility would be to demonstrate that lesbians were at least ordinary mothers, and therefore likely to be "as good as" heterosexual mothers in comparable social and economic circumstances. It seemed to me that the basis on which custody cases were argued needed to be challenged, that the focus should be on the ways in which lesbian mother families, like other families, met the basic and recurrent needs of their children, rather than on the mother's affectional preferences. This also meant to me that research needed to be more sociological and structural than psychological, shifting concern from how the mother's sexuality or the absence of a father would affect the children's development to the ways in which the daily lives of lesbian and heterosexual femaleheaded families would tend to coincide. 


\section{Popular Feminism and Feminist Scholarship: Assumptions about Motherhood}

Though the reasons for their conclusions varied, feminists of many backgrounds and theoretical orientations had tended to view motherhood as the source of the problem we all sought to address: why women are devalued, deprived, or oppressed in so many, if not all, of the world's societies. Some reasoned that women's reproductive specialization, and particularly their tendency to have primary responsibility for the care of children, determined the division of labor by sex, insofar as child care was incompatible with many economic roles dominated by men. ${ }^{18}$ Other focused on the symbolic impact of motherhood, seeing it as the basis for women's "otherness" in all cultures. ${ }^{19}$ Psychoanalytically inclined theorists called our attention to the intrapsychic level; ${ }^{20}$ those more concerned with social structure looked at the ways in which motherhood defined women's concerns on the more private level, blocking their acquisition of the tools needed for manipulation of the public domain. ${ }^{21}$ And many feminists, coming from less academic perspectives, also generated theories of women's oppression which focused on motherhood or reproduction as the "culprits" responsible for women's enslavement. ${ }^{22}$ While most early feminist analyses linked the oppression of women to the social and cultural organization of reproduction, many later "cultural feminists" instead emphasized ways in which motherhood endowed women with distinct (and possibly superior) moral or spiritual capacities. ${ }^{2.3}$

All of these perspectives tend to conflate motherhood and womanhood, as though they were interchangeable, mutually defining, and as though the status of woman could be entirely understood with respect to the meaning of motherhood in a particular situation. In the early period of feminist theorizing, the assumption that women's oppression was universal was accompanied by the notion that women must be viewed as victims of cultures they did not devise. Male dominance, or patriarchy, was simply there (and probably always had been), and women had to live with its consequences, somehow finding a way to manage their devalued situations. 
It seemed to me, however, that motherhood, rather than being a unitary phenomenon (a misapprehension further enforced by the single word we use to describe "mothers"), could also be viewed in a more dynamic fashion. I began to think of motherhood as a strategy for dealing with devalued status, at the same time that it might be one of the causes of that status, and I approached motherhood specifically as an economic strategy. My early work on lower-class Latina immigrants, for instance, indicated that they tended not to see motherhood as a choice. Nevertheless, once women were mothers, their ongoing stratcgies all began from the resources offered by motherhood, sometimes involving highly self-conscious manipulations of ties with children. ${ }^{24}$

Lesbian mothers, I reasoned, would differ from the Latina mothers in that they could not avoid being more purposeful and self-conscious about their situations as mothers. In particular, those who had had their children outside of marital situations--that is, the women who had become mothers through donor insemination or adoptionprobably had entered into motherhood voluntarily, despite its supposed negative effects on future opportunity and access to the public domain. A central question, then, was why, if motherhood is the source of women's devalued status, do women become mothers? And why, more to the point, do women who perceive themselves as having other options, especially women who cannot become mothers by accident, purposefully propel themselves into this problematic situation?

At the time I bcgan to plan my research, virtually nothing apart from limited clinical rcports had appeared on lesbian motherhood in the scholarly literaturc, ${ }^{25}$ though scveral psychological studies got under way about the same time I bcgan. These few were all tightly controlled comparatives studies of children of lesbian mothers and matched samples of children from "fathcr-absent homes," all of which isolated variables presumed to indicatc cmotional adjustment or "normal" sex-role learning. ${ }^{26}$, What little I could find in popular sources mainly took the form of personal narratives appcaring in feminist and gay media as well as in Mom's Apple Pie, thc newsletter of the Lesbian Mothers National Defense Fund. ${ }^{27}$ I also located nu- 
merous accounts of custody problems, ${ }^{28}$ and a small body of more polemical writing about the place of motherhood in a future Lesbian Nation. ${ }^{29}$ Discussions of motherhood appeared with some regularity in radical feminist/separatist publications such as Off Our Backs and The Firies, with debates frequently focusing on the "problem" of male children and on the need for more collective forms of child rearing.

Since there were so few scholarly works on lesbian mothers, I depended heavily on scholarly (and sometimes popular) writings on divorce, unwed mothers, matrifocality, and single mothers in poverty ${ }^{30}$ On the basis of reports of custody problems and anecdotal material on lesbian mothers in popular works, I anticipated a range of problems and issues likely to be significant for lesbian mothers. The literature on lesbianism available during this period either was silent on the subject of motherhood or mentioned it only briefly; far more attention was devoted to questions of etiology and debates about pathology, along with speculation about sexual behavior and psychological status, ${ }^{31}$ though an important article by John Gagnon and William Simon placed great emphasis on pervasive similarities in the socialization and emotional experience of lesbians and heterosexual woman, thus indirectly suggesting that lesbians could be mothers. ${ }^{32}$

The research design I finally settled on, organized as a comparative study of single mothers and developed to meet the requirements of a federal funding agency, was grounded in a growing conviction that lesbian mothers were really "just" single mothers who faced some additional challenges. (The Appendix provides details on my research design and methods.) In other words, I could pursue my desire to demonstrate the lack of significant differences between lesbian mothers and others by framing lesbian mothers as "single mothers." Once lesbian mothers had been transformed into single mothers, a deviant but relatively benign category, I could more easily make my case for tolerance.

Framing lesbian mothers as single mothers was already a congenial perspective, I should add, in that it conformed to my underlying notion that women, regardless of situational variations, share fundamental common experiences, and that these experiences lead to, or 


\section{[8] Lesbian Mothers}

somehow are implicated in, their predicament in patriarchal society. As Rayna Rapp has noted, "single mother" (like "working mother") is a symbol in transition, no longer designating the strictly stigmatized "unwed mother" or the remaining parent in a "broken home," but rather signifying the growing validation of a common American domestic arrangement. ${ }^{33} \mathrm{My}$ thinking was that lesbian mothers, insofar as they share with other single mothers particular material circumstances, most of which are related to the absence of an adult male from the domestic unit, also are likely to be subject to similar sorts of "oppression;" that is, low incomes, difficulty obtaining adequate housing and child care, feelings of being overwhelmed by responsibility for the children, low prestige in the community, and so forth. I did anticipate some differences as well, reasoning that lesbian mothcrs would be more vulnerable to custody litigation or threats of such litigation, and that lesbian mothers' access to traditional-that is, kinbased-systems of social support would be impaired.

What were the consequences of this strategy for the findings generated by the research? There can be little doubt that the final design of the project-comparative, framed in a quantitative mode, and ultimately tied to the notion that lesbian mothers could be best understood with reference to other (heterosexual) single mothers-had a significant impact on the conduct of the inquiry and on the kinds of results the research generated. Despite the fact that the focus on "single motherhood" as a unifying theme was primarily a strategy intended to make the study workable within the federal grant context, the terminology started to take on a life of its own as the study progressed. Single mothers began to scem like a bounded group, similar to an ethnic group or a tribe, rather than the reification of a label I had chosen to use for reasons of convenience. Questions framed from this standpoint made it seem the "lesbian" was something to be added to "single," the source of additional oppression, but not the source of fundamental difference. ${ }^{34}$

I knew from the beginning that "single mother" was not necessarily the way either lesbian or heterosexual mothers designated themselves-that is, not a "native category"-but reminded myself that the term was just shorthand for the general civil status of the 
mothers I was studying. From a purely legal point of view, they were "not married" to the fathers of their children, a fact that influenced, or sometimes even determined, their economic status, their position in the judicial system, and the nature of the daily dilemmas they faced as parents, particularly with respect to the problem of bearing the primary responsibility for the survival and well-being of their children.

\section{Narrative and Identity}

Starting with the goal of destigmatizing lesbian mothers, of proving that they were just as worthy of custody of their children as nonlesbian mothers facing comparable material challenges, I was gratified to find that the narratives of both lesbian and nonlesbian mothers focused on very similar experiences in their roles as heads of their families. For example, despite my early expectations that lesbian mothers would tend to substitute friendship for kinship ties in constituting support networks, my interviews showed something very different. Lesbian mothers, no less than heterosexuals, regarded family members, particularly their parents, as the most reliable sources of support and as their most appropriate resources when times were hard. ${ }^{35}$ This pattern did not seem to be seriously altered by the strains that the women's revelation of their lesbianism often imposed on family relationships. Though some of the women endured angry confrontations or periods when they and their relatives ceased communication, most commonly the passage of time seemed to make some sort of accommodation possible. Mothers I interviewed explained that their parents could not endure a permanent rupture, that while they often continued to raise objections to some aspect of their daughter's "lifestyle," they were able to find a basis for compromise. Family ties were simply too profound to be broken permanently, they explained, sounding much like heterosexual mothers who had disagreements of other sorts with their families.

Similarities between the accounts of lesbian and heterosexual mothers were not limited to their relationships with their families. Mothers in both groups also reported that they went to great lengths 


\section{[10] Lesbian Mothers}

to encourage their children's relationships with their fathers, even with considerable provocation to the contrary; that they tended to seek out other single mothers, regardless of sexual orientation, as friends; that their friendships with people who wcre not parents became attenuated and fraught with mistrust over time; and that they expected relatively little support from sexual partners, whether they were women or men. Mothers who faced a custody battle or the threat of one mounted very similar strategies of avoidance and appeasement, whether the women were lesbian or not.

Similarly, the language lesbian mothers used to discuss what it meant to them to be mothers echoed that of heterosexual mothers. The association of being a mother with "goodness" was striking, as was pervasive imagery of motherhood superseding and overwhelming other sources of identity. The women spoke with equal intensity of their sense that motherhood formed the focus of their identities, both materially and spiritually, and that it gave value and significance to their lives.

The search for identity through motherhood was a quest that lesbians seemed to share with unmarried heterosexual women. Many mothers described themselves as having lived without a focus or worthwhile purpose until they had a child. They saw motherhood as having stimulated the emergence of creativity and industry, so that they now lived more productive, worthwhile lives. A few lesbian mothers used the word "single" to refer disparagingly not to women without partners but to women who had no children. They described such women as having significantly different (and less worthy) interests and goals, and spoke with some intensity of their motherhood as a more crucial determinant of their identities than thcir lesbianism, a more compelling indicator of loyalties and affiliations. Such usages alerted me to the need to examine motherhood not only as a practical condition but as a moral domain, onc that enables mothers of all kinds to demand public recognition and to make claims to cultural, if not material, benefits.

But did this mean that something about being a single mother was a shared experience for both lesbian and heterosexual women? My growing understanding that these accounts would be best interpreted 
as having cultural, rather than descriptive, significance pointed to the problematic nature of the "single mother" label as a way to think about these women. Lesbian and heterosexual mothers framed their narratives similarly and selected particular experiences as meaningful and worth describing as instances of "being mothers." But strong feelings about the burdens associated with motherhood, combined with a focus on motherhood as the core of identity, tended to eclipse substantive differences in the routine life experiences of lesbian and heterosexual mothers, differences that often emerged indirectly. Further, information gleaned from interviews with others in informants' social networks sometimes yielded contradictory accounts of relationships and events. I began to consider the possibility that the narratives of lesbian and heterosexual mothers were similar not necessarily because the women's experiences were comparable but rather in spite of the fact that they may not have been.

From this perspective, it became clear that lesbian and heterosexual mothers, despite concrete differences in their daily experiences, use narratives to construct their experience as mothers, and by extension as women, from shared cultural elements. Their narratives are shaped by, among other things, concerns with achieving a satisfying individual identity, and particularly with demonstrating some measure of independence. They are heavily influenced by relatively conventional gender expectations centered on women's special vocation for nurturance and altruism and men's disinterest in parental responsibilities. They are further influenced by notions about the essential impact of motherhood on one's identity; more than other aspects of identity, motherhood is seen as being driven by elemental, probably biological, forces not readily controlled by the individual. These forces make mothers and nonmothers different in fundamental ways, and work to undermine desires they may have to understand and support each other. Finally, the narratives reveal a strong acceptance of the specialness of kinship as a source of support and continuity. While mothers often express frustration with particular dimensions of their relationships with blood relatives, they also demonstrate a commitment to transcend these difficulties, and thus to strengthen their bonds with their children. 


\section{[12] Lesbian Mothers}

\section{Feminist Anthropology and the Search for Women's Experience}

The shifts in my thinking paralleled changes in process in anthropology during the years I worked on this project, as ethnographers' concerns moved from an emphasis on positivistic description to an interest in the more relative, and explicitly negotiated, aspects of the production of ethnographic knowledge. Despite the recent preoccupation with postmodernist thought as the source of these changes, ${ }^{36}$ the beginnings of this concern emerged earlier in social anthropology, in part as a reaction against the rigidity of structural models. ${ }^{37}$ It might be argued, in fact, that these changes set the stage for the emergence of feminist anthropology in the mid-I970s. ${ }^{34} \mathrm{De}-$ spite debates over other issues, feminist anthropology of all stripes came to be centrally concerned with the ways in which women's experience in male-dominated cultures amounted to more than what might be predicted from an inspection of the most formal level of organization. Early feminist ethnographers sought to direct our attention to how women themselves described their experience, often producing accounts that differed sharply from those produced earlier by male ethnographers. ${ }^{39}$ These researchers were concerned both with investigating the informal level of sociocultural organization more thoroughly and with giving women a voice they had previously been denied. ${ }^{40}$

In this respect, feminist anthropology moved decisively in the same direction as feminist scholarship in other fields and popular feminist writing. On the one hand, the idea was that women's experience had been poorly documented because scholars failed even to ask questions about women; as the "other," women were not assumed to make significant contributions to culture, and hence it did not seem unreasonable to produce an ethnography that made virtually no mention of women's activities, or, when it did, confined such discussion to stereotypical domains of childbirth and marriage. Here the problem was that women's behavior was ignored.

On the other hand, feminist critics pointed out that even when anthropologists asked questions about women, they rarely sought 
women's own voices as the authoritative sources of information about them. The feminists' concern was not so much with what women did or were observed to do-such data could not help but be influenced by the observer's culturally deternined expectations. Rather, the issue was more how to establish a context to listen to what women said about themselves, to discover how they framed their experience, what they made of their situations, quite apart from what any particular observer might claim.

The focus in anthropology on gathering women's own accounts of their experience is closely related, then, to a similar impulse in the wider domain of feminist scholarship to produce "feminist methodology." 41 And efforts to develop this methodology were inspircd, in turn, by the process of collective understanding-consciousness raising-by which Second Wave feminism, particularly in its radical incarnation, built its analysis of patriarchy. ${ }^{42}$ In practice, this meant that each woman would tell her "story" to other women belonging to her small group; each would listen to the story without interrupting. As the stories unfolded, patterns and convergences would emerge. The outcome of the process was a collective understanding of the ways in which Woman is constructed in culture. Of course, participants in this process, likc anthropologists in the field, tended to take the accounts so collected more literally, or perhaps more concretely, than we might now consider appropriate, and this is where my method in the early stages of this project brought together my commitment to feminism and my I960s training as an anthropologist: I thought I could know what women "did" on the basis of what they told me. This assumption provided a fundamental rationale for the organization of my data according to specific kinship and social domains (relations with relatives, children, friends, ex-husbands). Taking a point of view influenced by social network theory, ${ }^{43} \mathrm{I}$ saw people in each of these domains as resources that could be mobilized as needed and that would shape both the lesbian mother's perception of her location in an interactive web and her ability to cope with the various difficulties, both material and moral, she would be likely to encounter. 


\section{[14] Lesbian Mothers}

To some extent, feminist scholars now working to overturn the excesses of the earlier preoccupation with universal female subordination, principally represented by new critical writings by women of color, have made a similar error. These authors have attempted to extricate themselves from the hegemony of a single view of "woman" (what Gloria Anzaldúa has infelicitously called "whitcfeminism"), highlighting the importance of cultural and historical variability in the shaping of women's experience and definition of themsclves. ${ }^{44}$ But here again the personal account becomes reified as literal truth, and the more subtle process of negotiation and self-definition tend to be lost. ${ }^{45}$ If being a "woman" no longer detcrmines the fate of a female person, then race or class in one view, ${ }^{46}$ sexual orientation in another, ${ }^{47}$ does the job instead, reducing women (or pcople) to straightforward representations of the claims they made in talking about themselves.

Some feminist scholarship, happily, has managed to merge the concern of feminist methodology with the primacy of experience with an understanding of the contingent and negotiated nature of narrative, leading to a singular grasp of the personal narrative as a reflection of a cultural process rather than as a videotape manqué or literal account of observable behavior. Women say what they do, or what they did, as a way of constructing key notions of self, and in the process go on to construct gender. More than hopelessly unmeasurable indicators of gender (or race, or class, or sexuality) as it affects opportunities or interactions, personal narratives offer us a chance to see how women account for themselves, make sense of their situations, and designate themselves in relation to others-how they, in fact, negotiate their identities in collaboration with or in opposition to prevailing cultural expectations.

Innovative work using the personal narrative in this way has already been done, often leading to ventures that break down traditional disciplinary boundaries. ${ }^{48}$ Carolyn Steedman has pointed to the highly variable views of women's lives generated by shifts between the perspectives of mother and daughter, shifts that are not determined by class but that yet reflect the constantly changing impact of 
class on the views of the two protagonists, mother and daughter. Perhaps most important, the daughter/narrator in her volume is also the historian/analyst, so her construction of her own experience in relation to that of her mother moves along two axes simultaneously. ${ }^{49}$ Similarly, Renato Rosaldo has shown that the hunting stories of the Ilongot of the Philippines not only are accounts of how particular hunts proceed but are occasions that help the hunters make particular kinds of cultural points. "Huntsmen in fact seek out experiences that can be told as stories. In other words, storjes often shape, rather than simply reflect, human conduct. "50

Faye Ginsburg has taken a similar approach to her study of activists on both sides of the abortion debate. Working in a small, relatively homogeneous community, Ginsburg collected accounts she calls "procreation stories" of women's maternal histories. She shows persuasively that both "pro-choice" and "pro-life" informants arrive at the particular commitments they have made on the basis of similar, if not substantially identical, cultural positions, framed largely in terms of views of nurturance and family generally shared throughout the community. ${ }^{51}$ Women's politics, then, cannot be said to be derivative of distinct cultural positions, but rather unfolds as women's specific experiences interact with values they already accept.

Lesbian mothers are a good population for examining these kinds of ideas, in part because they seem to embody contradictions. On the one hand, insofar as lesbianism and motherhood seem to be culturally (if not biologically) incompatible, they transcend or challenge the ordinary organization of gender in American culture, which conflates "woman" and "mother" and defines lesbians as neither. In this sense, claiming the jdentity of lesbian mother may be construcd as an instance of resistance to prevailing sexual politics.

But in becoming mothers, lesbians join heterosexual women in a particular organization of identity which partakes of mainstream gender ideology. The notion that motherhood (or womanhood, by extension) supersedes other dimensions of identity is espoused by both lesbian and heterosexual mothcrs. Lesbian mothers not only encounter the same material conditions as other mothers but demand access 


\section{[16] Lesbian Mothers}

to the same cultural and symbolic resources available to nonlesbian mothers. This suggests that the resistance to conventional gender ideology implied by the oxymoronic status of the lesbian mother can be superseded or compromised by its resolution of the "problem" of lesbian identity. Though I do not argue that lesbians become mothers purposefully in order to regularize their status, as a direct response to stigma, I do contend that motherhood indirectly enables women (whether lesbian or heterosexual) to claim a specific location in the gender system.

The centrality of images of nurturance and altruism in mothers' narratives about the meaning of motherhood, for example, stands in stark contrast to the pervasive stereotypes of decadent, selfish, and above all nonprocreative behavior attributed to gay men, and by extension to lesbians. Similarly, the responsibilities associated with motherhood clearly contrast with the image of homosexuality as "arrested development" popularized by psychoanalytically oriented mental health professionals. ${ }^{52}$

One of the consequences, then, of both the material and symbolic predicament faced by lesbians (and by single heterosexual mothers) is that solutions to a range of problems generated by the traditional cultural/gender system are themselves embedded in that traditional system. The multilayered problems caused or complicated by financial limitations, the perceptions of oneself as isolated and at odds with the wider culture, and the struggle to establish a positive identity for oneself and for one's family are difficulties shared by all mothers whose circumstances are not conventional. The resources available to deal with these difficulties continue to be relationships with biological family, friendship ties with other mothers, and an elaboration of an ideology of consanguineal (blood) kinship. Resistance and complicity overlap and define each other, making it impossible to judge any particular strategy as one or the other.

These observations do not really change my view that lesbian mothers are not systematically different from other mothers who share some similar concrete problems. On one level, to be sure, all mothers in our society must operate under similar material conditions; all mothers confront a range of powerful structural constraints 


\section{Looking for Lesbian Motherhood [17]}

to which they must craft strategic responses. But these strategies are also articulated in a cultural context; they represent the operation of a shared cultural process, one that can be traced as easily in the accounts of the lesbians as in those of their heterosexual counterparts. Both lesbian and heterosexual mothers participate in the implementation of gender on the same basis, constructing their identities from mutually available elements and negotiating identity in ways shared with us all. 
